shattering noise and possible death from blast, gas, or bombs, if not from shock. These patients unfortunately would be those who are most seriously ill and in need of constant attention. They would include many waiting for, or recoverin f from, major operations. All this could be avoided by developing the idea of country hospitals attached to central town hospitals on the lines of the pioneer work which the Princess Elizabeth of York Hospital for Children is carrying out at Banstead, in Surrey. It is particularly apt that a hospital for town children should take the initiative in this way, for the arguments advanced above are pathetically applicable to child patients. The advantages of country hospitals in peace-time are obvious and have already been stressed in the Press.

\section{Control of Small-pox}

Dr. C. B. Drew (Abu Usher Civil Hospital, Sudan) writes: I would like to support the views of Dr. A. G. Newell published in the Journal of December 31, 1938 (p. 1392). Variola inoculation is used in parts of this country, among some of the more primitive people, with disastrous results. It was extensively practised by the Arabs during the Mahdia (1883-98), and is still remembered by them as a scourge ; in a recent vaccination drive here one of the greatest difficulties was to persuade the native that he was being vaccinated (which he does not understand) and not "variolated." There has been some confusion betwixt armto-arm vaccination, which, so far as I know, is not employed here, and variola inoculation, which in parts is extensively practised. Jenner would have been highly gratified with the faith placed in vaccination; one successful vaccination is believed by the native to confer immunity for life.

\section{Heart Failure and Sudden Death}

Colonel G. F. RowcrofT (Coonoor, S. India) writes: What is the cause of death in so-called heart failure? Does heart failure cause death, or is it that death causes heart failure? I suppose most of us think the former, but it seems doubtful, and the latter seems the more probable. We all know of these cases of sudden death, and they are usually very similar. To mention only one or two as examples which come to my mind. A lady was seated with her two sisters, talking quietly together. Suddenly her head dropped, and going up to her they found she was dead. A man was seated talking quietly with his friends. He stopped talking, and they found he was dead. A man was in his garden playing with his children, apparently quite well. He suddenly fell dead. One might mention many others. There is a remarkable similarity in them all. There appears to be no preceding pain or other warning, though in some cases they have been known to have "weak hearts." Why should such sudden heart failure cause death? In spite of the " all or nothing " action of the heart one would expect some slight previous warning. Are such people really dead? Or (if the remedy could be applied) would immediate heart stimulation, by needling, injection of novocain, manual massage through the appropriate incision, etc., resuscitate them, as it can in surgical cases? One never hears of such casualties "coming round" again, yet we know of many instances, usually surgical cases under anaesthesia, where the heart has stopped beating for quite definite periods and has been started again, and the subjects revived. The interesting article on the regulation of arterial pressure in the Journal of January 28 (p. 172) tends to show that the long-held belief in the vasomotor centre in the medulla, maintained in the first instance by Starling, may require revision, and that vascular control may be governed by impulses from the carotid sinus and aortic arch. But a perusal of the very exact experiments Starling gives seems to show that there is such a centre in the medulla; he gives the exact spot. May not it and the sinus and arch all work together? May it not be that there is what one might call a "vital centre," or "life centre," somewhere in the body, possibly in the heart itself, which controls somatic life; and that when this is in some way overcome, heart failure automatically and necessarily follows? I have, on service, been close to a man shot through the heart, and he fell dead practically instantaneously. Why, if some such centre was not put out of action? He should have lived for at least a few seconds. But I have also seen a wild animal shot with an explosive bullet, and the heart absolutely shattered, yet it has run for about 100 yards, and many tiger shooters know of such cases, which of course is rather against the idea of-in their case at least-a "vital centre" in the heart.

\section{Tonsillitis}

Dr. J. W. Thомpson (Walsall) writes: I have been very much impressed by cases of tonsillitis, not necessarily of the virulent streptococcal type, which have been accompanied in the early stages, throughout the illness, or in the later stages by abdominal pain, usually mild in nature. This pain is evidenced by muscular rigidity and by tenderness situated in the vast majority of cases in the right lumbar and iliac regions. My interpretation of these signs is that coincidently with the tonsillitis there is a widespread infection to a greater or lesser extent of the lymphoid tissue of the alimentary canal. Especially does this apply to the terminal ileum, where Peyer's patches abound, and to the appendix, in whose walls lie aggregations of lymphoid tissue. The so-called "gastric influenza" I look upon as a mild infection of these self-same lymph patches, its origin thus being in the terminal ileum and showing an analogy to tuberculous infection. In support of this idea it may be noticed that in children the gastro-intestinal tract very often bears the brunt of the initial stages of infection-vomiting, diarrhoea and abdominal pain being the precursors of an attack of tonsillitis.

\section{William Hunter's Coins}

Dr. A. Piney (London) writes: Mr. Sampson Handley's reference to the collection of coins made by William Hunter (Journal, February 18, p. 313) reminded me that I possessed a copy of the catalogue entitled: Nummorum veterum populorum et urbium, qui in museo Gulielmi Hunter, asservantur, descriptio figuris illustrata. This large volume published in London in 1782, contains 354 pages of brief description of the individual coins, and sixty-eight plates on which the specimens are depicted. The copy I possess is marked in pencil in many places, as if the lists had been used to check the collection; and, in addition, there are pencilled descriptions above some of the illustrations. I's it possible that this may be the copy of the catalogue that was used by Hunter's executors when they examined his collection, or, even more thrilling thought, could the notes be in William Hunter's own hand? I am too poor a numismatist to know whether the volume is of interest and I am far too ignorant to decide whether the pencilled remarks are such as could have been made in the late eighteenth century. It would be of very great interest if someone learned in numismatics could give an idea of the history of this volume; and, equally, it would complete Mr. Handley's remarks if we could know what became of the great collection of coins.

\section{Dentists Register, 1939}

The Dentists Register for 1939 has now been published for the Dental . Board of the United Kingdom by Constable and Co., Ltd., price $12 \mathrm{~s}$., post free 12s. 6d. The total number of names appearing on January 1 of this year is 14,722 , being fifty-eight less than the figure for 1938, but sixteen more than the figure for 1937. Of these, 8,818 (59.9 per cent.) are registered with medical, surgical, or dental qualifications, the remainder being registered under the provisions of the Dentists Acts of 1878 and 1921. The number of names added by - registration was 408 , including fifteen foreign and seven colonial dentists.

\section{A Warning}

We are informed that several doctors in the West of England have been imposed upon by a traveller purporting to be a representative of a firm in Plymouth, who called upon them to demonstrate a new crêpe rubber bandage. One medical man ordered three each of two sizes by way of trial, and as the cost was small (13s. 6d.) he paid cash and was given a pencilled receipt on a printed form. The bandages not having arrived in three weeks' time, he wrote to the address given on the order form, detailing the circumstances of the order and asking to hear from the firm. Getting no reply, he sent a registered letter to the same address asking for delivery of the goods ordered or the return of the money paid. This letter was returned by the Post Office, the envelope marked "Unable to effect delivery."

\section{Corrigendum}

In the review of St. Thomas's Hospital Reports in our issue of March 11, page 507, an error was made in stating "no price given." The price of the volume is 10s. for nonsubscribers and 7s. 6d. for subscribers. 